\title{
WALTER RUBEN
}

Die Entwicklung von Staat und Recht im alten Indien 


\title{
DEUTSCHE AKADEMIE DER WISSENSCHAFTEN ZU BERLIN
}

\author{
Veröffentlichungen \\ des Instituts für Orientforschung
}

67

\section{WALTER RUBEN}

Die gesellschaftliche Entwicklung im alten Indien

II 
WALTER RUBEN

\section{DIE ENTWICKLUNG VON STAAT UND RECHT \\ IM ALTEN INDIEN}

A K A D E M I E - VE R L A G - B E RLIN

1968 
Erschienen im Akademie-Verlag GmbH, 108 Berlin, Leipziger Straße 3-4 Copyright 1968 by Akademie-Verlag GmbH

Lizenznummer: $202 \cdot$ 100/72/68

Hersteliung: IV/2/14 VEB Werkdruck, 445 Gräfenhainichen · 2956

Bestellnummer: 2013/67-II - ES 7 L + 14 F

31,- 